\title{
Anxiety associated with self monitoring of capillary blood glucose
}

\author{
AMY SHLOMOWITZ ${ }^{1,2}$, MICHAEL D FEHER $3,4,5$
}

\begin{abstract}
Aims: The aims were to evaluate (1) prevalence and contributing factors of anxiety to the finger prick method used to self monitor glucose: (2) whether individuals report avoidance of self monitoring due to fear of the finger prick method; and (3) levels of general anxiety.

Methods: Individuals attending a specialist diabetes outpatient centre, and who self monitored their capillary blood glucose concentrations, were invited to complete a standardised questionnaire to assess anxiety associated with the finger prick method blood glucose measurement, and general day-to-day anxiety.

Results: From 315 (58\% male) individuals with diabetes, finger prick anxiety was observed in $30 \%$ and general anxiety in $33 \%$. Positive correlations were found for finger prick anxiety with avoidance of testing and with general anxiety. Older individuals had less general anxiety and females reported greater anxiety to the finger prick method and general anxiety. There were ethnic differences in anxiety to the finger prick method and avoidance of testing, but not to general anxiety.

Conclusions: One third of a general diabetes outpatient cohort have general anxiety and anxiety to the finger prick method for glucose testing. There are important implications for both patients and health care professionals in identifying barriers to achieving improved diabetes control.

Br J Diabetes Vasc Dis 2014;14:60-63
\end{abstract}

Key words: finger prick anxiety, anxiety, diabetes, glucose testing, lancet,

\section{Introduction}

Self monitoring of blood glucose is routine practice for many individuals with diabetes. This requires a drop of capillary blood to

Advanced Diabetes Specialist Nurse, Beta Cell Diabetes Centre, Chelsea and Westminster Hospital, London, UK

Thomas Addison Unit, St Georges Healthcare, London, UK

Beta Cell Diabetes Centre, Chelsea and Westminster Hospital, London, UK

Diabetes Therapy Evaluation Network, London, UK

${ }^{4}$ CSRI, Warwick University, Warwick, UK

Address for correspondence: Miss Amy Shlomowitz

Thomas Addison Unit, St Georges Healthcare NHS Trust, London SW17

0QT, UK Tel: +44 (0)20 82666618 E-mail: amyshlom@hotmail.com

http://dx.doi.org/10.15277/bjdvd.2014.018

\author{
Abbreviations and acronyms \\ FPA \\ GAS \\ finger prick anxiety \\ general anxiety score \\ HADS hospital anxiety and depression score
}

be obtained by pricking the tip of a finger with a modified lancet. ${ }^{1}$ To date there is limited evidence evaluating anxiety to the finger prick method, in contrast to several studies assessing anxiety and phobia to self injection with needles used for subcutaneous insulin. ${ }^{2}$ This is set in a background for a diabetes group, where simple phobias and general anxiety are twice as common compared to the general population. ${ }^{3}$ Anxiety has also been linked to worse glycaemic control. ${ }^{4}$

The aims of the current study were to evaluate in a diabetes cohort (1) the prevalence and contributing factors of anxiety to the finger prick method used to monitor blood glucose concentration; (2) whether individuals avoid self monitoring due to fear of the finger prick method; and (3) levels of general anxiety.

\section{Patients and methods}

The study design was a cross-sectional questionnaire survey. Recruitment over a four month period included individuals with either type 1 or type 2 diabetes who attended for routine outpatient follow-up at the specialist Beta Cell Diabetes Centre of the Chelsea and Westminster Hospital Foundation Trust, London. Unselected patients, who were consented, completed a written questionnaire which assessed demographic and treatment details, aspects of anxiety to the finger prick method to measure glucose, and levels of general anxiety.

General anxiety was measured using the well known Anxiety Subscale of the Hospital Anxiety and Depression Scale (HADS). ${ }^{2}$ Anxiety to the finger prick method defined as FPA was assessed by using the previously published injection anxiety measure ${ }^{2}$ with the questions being tailored to focus on the finger prick method rather than the needle injection used to administer insulin (Appendix 1 available online at www.bjdvd.com). Components assessed were attitudes to self monitoring of blood glucose, and subjective current physical and psychological responses prior to and at the time of testing. Participants were given a score according to responses (score categories: unconcerned $=^{\prime} 0^{\prime}$, concerned $={ }^{\prime} 1{ }^{\prime}$, mild $/$ moderate anxiety $=' 2$ ' and fear $=$ ' 3 ') when they actually tested their blood glucose. An affirmative answer to the question about physical symptoms prior to monitoring, received 1 point for each symptom with a maximum possible score of 4 points. The other 4 questions scored 1 point for an 
Figure 1. Examples of lancing devices for finger prick blood glucose testing.

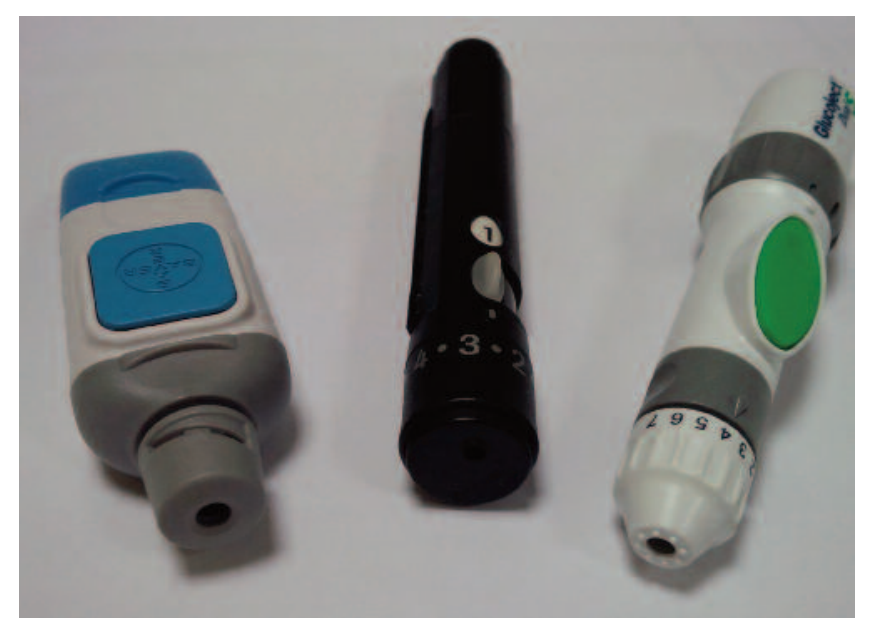

affirmative answer. For the whole test, the minimum total score obtainable was 0 with a maximum total score of 14 . A total score of $\geq 3$ was used to classify those as having at least some anxiety to the finger prick method. ${ }^{2}$ An additional assessment was made to gain further details on reasons why an individual might avoid the finger prick method of glucose monitoring: The questions asked were: "do you test less than recommended or not test at all due to dislike/fear of needles or other reasons?" Participants could answer 'yes', 'no', or state other reasons.

To explore general psychological factors further, general anxiety was assessed by the anxiety subscale of the $\operatorname{HADS}^{5}$ (Appendix 2 available online at www.bjdvd.com). A GAS of $\geq 8$ (the minimum score being 0 and maximum 21) was used as the threshold to identify anxiety according to previous published studies. ${ }^{6}$

The study evaluated responses of those undertaking the finger prick method and did not assess which specific device was used. Most modern glucometers have the manufacturer's own finger prick device where the lancet is inserted into a delivery barrel where the needle is covered (see Figure 1). While the authors acknowledge that the pressure of release and the depth of the needle may influence responses, this was not assessed. Additionally, details of glycaemic control and any relationship with anxiety scores were not evaluated in this study.

Statistical methods used were Kendall's tau_b for rank correlations to investigate associations between anxiety to the finger prick with continuous variables such as general anxiety, age, disease duration, type of treatment, amount of testing, and avoidance of testing. A chi square test was carried out to evaluate whether FPA and general anxiety differed across categorical variables of gender and ethnic groups.

Ethical approval was obtained from Riverside Research Ethics Committee.

\section{Results}

From 350 outpatients invited to participate in the study, 315 completed the questionnaire (response rate of $90 \%$ ). The study group, with $58 \%$ male subjects, had a mean age of 47 (range 19 - 86) years. Ethnic groups comprised Caucasian (74\%), Asian or Asian British (11\%), black or black British (7\%), mixed (5\%), other / not specified (3\%). Treatments used were either insulin alone or in combination with oral glucose-lowering agents (54\%), oral glucose-lowering agents alone (40\%), or with diet alone (6\%).

\section{Self reported glucose monitoring}

From the study sample, 93\% reported that they performed routine self blood glucose monitoring, with $50 \%$ testing at least twice per day, 23\% testing once per day, 20\% testing at least twice per week, and only $7 \%$ testing once per week or less.

\section{Finger prick anxiety (FPA)}

FPA (Table 1) was observed in $30 \%$ of patients; more women $(38 \%)$ than men $(24 \%)$ reported FPA $\left(x^{2}(1)=6.352, p<0.01\right)$; the Black group had a significantly higher proportion of FPA compared to other ethnic groups $\left(x^{2}(4)=17.680, p<0.01\right)$. There was no significant effect of age.

\section{General anxiety}

General anxiety (Table 1) was observed in 33\% of the group; anxiety was highest in the mixed ethnic group (43\%) and women (46\%); and in the 31-40 year age group. In the older

Table 1 Prevalence of anxiety to the finger prick method of blood glucose testing (Finger Prick Anxiety) and General Anxiety according to gender, ethnicity, and age in individuals with diabetes $(n=315)$.

\begin{tabular}{|c|c|c|c|c|}
\hline & Whole group & Gender & Ethnicity & Age groups \\
\hline $\begin{array}{l}\text { Finger Prick Anxiety } \\
\text { (defined as an FPA score >3) }\end{array}$ & $95(30 \%)$ & $\begin{array}{l}\text { Women } 51(38 \%) \\
\text { Men } 44(24 \%)\end{array}$ & $\begin{array}{l}\text { Black } 14(62 \%) \\
\text { Other } 5(50 \%) \\
\text { Asian } 14(42 \%) \\
\text { Mixed } 5(36 \%) \\
\text { Caucasian } 57(25 \%)\end{array}$ & $\begin{array}{ll}18-30 y r s & 9(26 \%) \\
31-40 y r s & 13(26 \%) \\
41-50 y r s & 16(29 \%) \\
51-60 y r s & 23(36 \%) \\
61-70 y r s & 22(34 \%) \\
71+\text { yrs } & 12(24 \%)\end{array}$ \\
\hline $\begin{array}{l}\text { General Anxiety } \\
\text { (defined as a GAS score >8) }\end{array}$ & $104(33 \%)$ & $\begin{array}{l}\text { Women } 56(46 \%) \\
\text { Men } 44(25 \%)\end{array}$ & $\begin{array}{l}\text { Mixed } 6(43 \%) \\
\text { Asian } 12(40 \%) \\
\text { Caucasian } 77(34 \%) \\
\text { Black } 6(33 \%) \\
\text { Other } 3(30 \%)\end{array}$ & $\begin{array}{l}18-30 y r s \quad 9(29 \%) \\
31-40 y r s 22(43 \%) \\
41-50 y r s 19(38 \%) \\
51-60 y r s 23(37 \%) \\
61-70 y r s 24(39 \%) \\
71+\text { yrs } 7(14 \%)\end{array}$ \\
\hline
\end{tabular}


Table 2 Prevalence of avoidance of testing and ethnicity $(n=313)$

\begin{tabular}{lllcr}
\hline Ethnicity & No avoidance & Avoidance (fear) & Avoidance (other) & Total \\
Caucasian & $63.9 \%(149)$ & $9.4 \%(22)$ & $26.6 \%(62)$ & $(233)$ \\
Asian/Asian British & $73.5 \%(25)$ & $17.6 \%(6)$ & $8.8 \%(3)$ & $(34)$ \\
Mixed & $66.6 \%(10)$ & $26.6 \%(4)$ & $6.6 \%(1)$ & $(15)$ \\
Black/Black British & $52.3 \%(11)$ & $28.5 \%(6)$ & $19.0 \%(4)$ & $(21)$ \\
Other Ethnic Group & $40.0 \%(4)$ & $50.0 \%(5)$ & $10.0 \%(1)$ & $(10)$ \\
Not specified & & & & $(2)$
\end{tabular}

age group (71+) there was less general anxiety (14\%).

Significant negative correlations were found between age and general anxiety (Kendall's tau_b $-0.119, n=292, p<0.01$ ), with younger adults reporting increased general anxiety, and general anxiety was more prevalent in women $\left(x^{2}(1)=13.041\right.$, $\mathrm{p}<0.01)$. There were no differences between the different ethnic groups.

\section{Avoidance by patients of finger prick blood glucose testing}

Avoidance of testing was significantly correlated with FPA (Kendall's tau_b 0.179, $\mathrm{n}=311, \mathrm{p}<0.001$ ) as well as FPA with general anxiety (Kendall's tau_b 0.225, $n=299, p<0.001$ ), demonstrating that those who avoided self monitoring had higher levels of FPA and higher levels of general anxiety.

In response to the additional specific question of avoidance of monitoring due to FPA, $13.7 \%$ of the total group and $19 \%$ of those who did not routinely monitor their blood glucose answered yes. Avoidance was higher in the non-defined ('other') ethnic group (Table 2$)$ and was statistically significant $\left(x^{2}(8)=\right.$ $27.104, p<0.001)$; however, age and gender were not.

Several reasons for avoidance of glucose testing were given (Table 3). While only one in five of this total group had specific anxiety to the finger prick method, other reasons for reduced testing (Table 3), unrelated to anxiety to the finger prick, were reported in 22.5\% and included: (Table 3) 'don't like it', 'forgetting', 'time pressure', 'pain', 'no need as readings stable', 'broken meter', 'laziness', 'fearful of glucose result', 'only test when unwell', 'not necessary to test', 'boring to test', 'self conscious of testing in public', and 'scared of infection'.

\section{Discussion}

This is one of the first studies specifically to assess anxiety to the finger prick method of blood glucose testing. The results show that a third of diabetes outpatients report at least some anxiety to the finger prick method of glucose testing in addition to increased levels of general anxiety. There is limited evidence about this important aspect of patient self management. Other studies have shown indirect evidence of levels of anxiety. In a Dutch study, fear of monitoring glucose was characterized by emotional distress and avoidance behaviour in a group of insulintreated individuals. ${ }^{7}$ A small group (less than 10\%) who scored highly in the Diabetes Fear of Injecting and Self-testing questionnaire were invited to participate in a behavioural avoidance test and nearly a quarter refused to perform an additional self blood
Table 3 Reasons for avoidance of self-glucose testing with the finger prick method

\begin{tabular}{ll}
\hline $\begin{array}{l}\text { Finger prick anxiety } \\
\text { specifically to the finger } \\
\text { prick method }\end{array}$ & $\begin{array}{l}\mathbf{1 3 . 7 \%} \text { prevalence in total } \\
\text { group (n=315) }\end{array}$ \\
$\begin{array}{l}\text { Reasons other than finger } \\
\text { prick anxiety }\end{array}$ & $\begin{array}{l}\text { Number in subgroup ( } \mathrm{n}=71) \text { who } \\
\text { had reasons other than anxiety } \\
\text { to finger prick method }\end{array}$ \\
\hline $\begin{array}{l}\text { Don't like (or no reason) } \\
\text { Forgetting }\end{array}$ & $17(23.9 \%)$ \\
Time pressures & $15(21.1 \%)$ \\
Injection pain / soreness & $9(12.6 \%)$ \\
Readings stable & $6(8.4 \%)$ \\
Broken meter or no strips & $6(8.4 \%)$ \\
Laziness & $4(5.6 \%)$ \\
Scared of result & $4(5.6 \%)$ \\
Test only when unwell & $3(4.2 \%)$ \\
Not necessary to test & $2(2.8 \%)$ \\
Boring & $2(2.8 \%)$ \\
Scared of infection & $1(1.4 \%)$ \\
Self conscious in public testing & $1(1.4 \%)$ \\
\hline
\end{tabular}

glucose test. $^{7}$

This study is consistent with previous studies on injectionrelated phobia, which is also more common in women than men. ${ }^{8}$

Differences were also found in general anxiety levels between gender and age groups. Older adults reported less general anxiety with a possible explanation that they may have developed effective coping strategies over time or have fewer stressors (for example, workplace-related) in their retirement. In addition, women reported higher levels of general anxiety, as has been highlighted in previous research. ${ }^{9}$ It has been argued that, despite the HADS having a sensitivity of $80-100 \%$ for identifying high anxiety levels, it is not diagnostic of general anxiety. It has been suggested that the proportion of cases, for example, on the HADS having a DSM-1V-R diagnosis of general anxiety is poor. ${ }^{10}$ One of the purposes, of the present study was to identify possible cases of general anxiety rather than diagnose generalised anxiety disorder, and the results concur with previous reports.

The strong association found for FPA with general anxiety corroborates previous findings with subcutaneous injection, ${ }^{2}$ and 


\section{Key messages}

- A third of diabetes outpatients report some anxiety to the finger prick method of glucose testing and also general anxiety.

- Females report greater anxiety to the finger prick method as well as general anxiety and older individuals have less general anxiety.

- This highlights two separate management strategies such as practical / educational and psychological intervention strategies, for example CBT

supports the notion that high levels of injection anxiety are associated with high levels of general anxiety and suggests that methods to decrease general anxiety may have a positive effect on reducing injection anxiety and needle phobia.

Despite the high proportion of FPA, the study found a large proportion of participants claiming to monitor their blood glucose. Of those reporting a reduced frequency of testing, a considerable proportion reported pain as the reason and this is consistent with previous research with avoidance of insulin injections. ${ }^{11}$ A USA based study found that 6\% (of 1895 participants), reported fear of needles as a reason for reduced testing, and of the participants not monitoring their blood glucose, $14 \%$ reported a fear of needles..$^{12}$ In the present study (Table 3), 32\% of the total group avoided glucose testing due to either dislike (with no reason stated) or injection pain, while $26 \%$ forgot or cited 'laziness'. One in eight subjects considered 'time pressure' as the reason for avoidance, while $5 \%$ were scared of the result or infection and a further $5 \%$ had technical issues or no testing strips. This highlights two distinct potential management strategies: a practical / educational strategy and psychological intervention strategies, such as cognitive behavioural therapy. In our view psychological intervention would be best to manage the reasons reported including specific 'anxiety' / 'dislike' / 'scared responses' while 'forgetfulness', 'time pressures', 'broken meters' could potentially be remedied by education and appropriate practice support targeting these issues.

Possible limitations of the study were that the assessment of FPA was undertaken using a self-reported method derived from injection anxiety assessment and self reported rather than observed behavioural characteristics. Some psychological symptoms are similar to physical responses to a low glucose and may be confounders when assessing feelings to undertaking the finger prick. The type of device used may also be a determinant of the response. Despite using questions from established psychological assessments, further work is required to refine and validate the scoring system of injection anxiety with regard to all groups within diabetes.

The present study, by assessing FPA and general anxiety, places in context the recent findings that psychological reasons for not monitoring blood glucose are not always addressed in diabetes clinics. ${ }^{11}$

\section{Conclusions}

The high levels of FPA and general anxiety observed in the current study highlight that professionals should be sensitive to the psychological factors relating to self blood glucose monitoring with the finger prick method. In those who cited forgetfulness, laziness or time pressure and technical issues, further diabetes education strategies could have a defined focus.

Increased awareness of the problem plus more specific assessment tools should identify those who might benefit from psychological treatments including cognitive behavioural therapy techniques. In extreme cases identification and referral for specialist psychological input may be warranted. These strategies may improve the glycaemic control, and general wellbeing of those individuals.

\section{Conflict of interest None Funding sources None}

\section{References}

1. Harris MI, Cowie CC, Howie LJ. Self-monitoring of blood glucose by adults with diabetes in the United States population. Diabetes Care 1993;16:1116-23. http://dx.doi.org/10.2337/diacare.16.8.1116

2. Zambanini A, Newson RB, Maisey M, Feher MD. Injection related anxiety in insulin - treated diabetes. Diabetes Res Clin Pract1999;46:239-46. http://dx.doi.org/10.1016/S0168-8227(99)00099-6

3. Green L, Feher MD, Catalan J. Fears and phobia in people with diabetes. Diabetes / Metabolism Research and Review 2000;16:287-93. http://dx.doi.org/10.1002/1520-7560(2000)9999:9999<::AIDDMRR123>3.0.CO;2-T

4. Anderson RJ, De Groot M, Grigsby AB et al. Anxiety and poor glycaemic control: A meta-analytic review of the literature. Int J Psych Med 2002; 32:235-47. http://dx.doi.org/10.2190/KLGD-4H8D-4RYL-TWQ8

5. Zigmond AS, Snaith RP. The Hospital Anxiety and Depression Scale. Acta Psychiatr Scand 1983;67:361-70. http://dx.doi.org/10.1111/j.1600-0447.1983.tb09716.x

6. Allsup SJ, Gosney MA. Anxiety and depression in an older research population and their impact on clinical outcomes in a randomised controlled trial. Postgrad Med J 2002;78:674-77.

http://dx.doi.org/10.1136/pmj.78.925.674

7. Mollema ED, Snoek FJ, Heine RJ, Van der Ploeg HM. Phobia of self-injecting and self-testing in insulin-treated diabetes patients: opportunities for screening. Diabet Med 2001;18:671-74. http://dx.doi.org/10.1046/j.1464-5491.2001.00547.x

8. Nir $Y$, Paz A, Sabo E, Potasman, I. Fear of Injection in Young Adults: Prevalence and Associations. Trop/ Med Hygiene 2003;68:341-44.

9. Thomas J, Jones G, Scarinci I, Brantley P. A Descriptive and Comparative Study of the prevalence of depressive and anxiety disorders in low-income adults with type 2 diabetes and other chronic illnesses. Diabetes Care 2003;26:2311-17. http://dx.doi.org/10.2337/diacare.26.8.2311

10. Kohen D, Burgess AP, Catalan J, Lant A. The role of anxiety and depression in quality of life and symptom reporting in people with diabetes mellitus. Quality of Life Res 1998;7:197-204. http://dx.doi.org/10.1023/A:1008817812520

11. Snoek FJ, Malanda UL, de Wit M. Self-monitoring of blood glucose: psychological barriers and benefits. EDN 2008;5:112-15.

12 Burge MR. Lack of compliance with home blood glucose monitoring predicts hospitalization in diabetes. Diabetes Care 2001;24:1502-03. http://dx.doi.org/10.2337/diacare.24.8.1502 
Appendix 1. Finger Prick Anxiety (FPA)

(Please circle or tick)

1. How would you describe your general feelings about testing your blood glucose with the finger prick needle?

\author{
Unconcerned \\ Concerned \\ Mild / Moderate anxiety \\ Fear
}

Yes / No

3. When you actually test your blood glucose with the finger prick needle, how would you describe your feelings?

4. Have you ever avoided testing your blood glucose because of any of these feelings? Yes / No

5. If you had to test your blood glucose more frequently, would this trouble you? Yes / No

6. Does your feeling about blood glucose testing interfere with your daily life? Yes / No

7. Have you developed any of the following before testing your blood glucose?

Palpitations / Pounding heart

Sweating

Trembling or shaking

Feeling short of breath or smothered

Unconcerned

Concerned

Mild / Moderate anxiety

Fear

Feeling of choking

Chest pain or discomfort

Nausea or 'tummy pains'

Dizziness / unsteady / light-headed or faint

Feelings of being detached from yourself or unreal

Fear of losing control or going crazy

Fear of dying

Numbness or tingling sensations

Chills or hot flushes

Yes / No
Yes / No
Yes / No
Yes / No
Yes / No
Yes / No
Yes / No
Yes / No
Yes / No
Yes / No
Yes / No
Yes / No
Yes / No

Scoring: Response for questions 1 and 3 were ranked from 0 to a maximum of three and questions 2,4,5, \& 6 scored one point for an affirmative answer. Individual responses for question 7 scores 1 point (with a maximum of 4 points). The minimum score obtainable was zero to a maximum 14. 
Appendix 2. Anxiety subsection of the Hospital and Anxiety Subscale (HADS-A)

(Please circle one letter only for each question)

1. I feel tense or 'wound up':
A Most of the time
B Lot of the time
C Occasionally
D Not at all

2. I get a sort of frightened feeling as if something awful is about to happen:
A Very definitely and quite badly
B Yes, but not too badly
C A little, but it doesn't worry me
D Not at all

3. Worrying thoughts go through my mind:
A A great deal of the time
B A lot of the time
C From time to time but not too often
D Only occasionally

4. I can sit at ease and feel relaxed:
A Definitely
B Usually
C Not often
D Not at all

5. I get a sort of frightened feeling like 'butterflies' in the stomach:
A Not at all
B Occasionally
C Quite often
D Very often

6. I feel restless as if I have to be on the move:
A Very much indeed
B Quite a lot
C Not very much
D Not at all

7. I get sudden feelings of panic:
A Very often indeed
B Quite often
C Not very often
D Not at all 